\title{
Effects of Interleukin 2 on Cardiac Function in the Isolated Rat Heart
}

\author{
P. A. Sobotka, J. McMannis, R. I. Fisher, D. G. Stein, and J. X. Thomas, Jr. \\ Departments of Medicine and Physiology, Loyola University of Chicago, Stritch School of Medicine, Maywood, Illinois 60153
}

\begin{abstract}
Adoptive immunotherapy with IL 2 is associated with severe cardiovascular toxicities including peripheral and pulmonary edema, hypotension decreased systemic vascular resistance, increased heart rate, and an increased cardiac index. The purpose of this investigation was to determine whether IL 2 alone or in combination with lymphokine-activated killer cells (LAK) cells depress cardiac function using the isolated, perfused, working rat heart preparation. Male Sprague-Dawley rats (250-350 g) were anesthetized and the hearts were removed and placed on the perfusion apparatus. Hearts were perfused with oxygenated Krebs-Henseleit buffer (KHB), or oxygenated KHB containing IL 2 alone, IL 2-Media (cell culture media supplemented with 1,500 U IL 2/ml), LYMPH (cell culture media from cultured mononuclear cells from healthy volunteers), or LAK (cell culture media from cultured lymphocytes harvested from patients receiving IL 2/LAK in the presence of $1,500 \mathrm{U} / \mathrm{ml}$ IL 2). The cells were removed before perfusion $(n=9)$. Cardiac output and coronary flow were measured at 20-min intervals with preload constant (afterload varied or afterload constant (preload varied). The results indicate a significant depression in cardiac function in hearts treated with LAK. This depression was evident at 20 min and was more pronounced at $60 \mathrm{~min}$. Washout of the KHB plus LAK reversed this depression. Thus, IL 2-stimulated/ cultured human mononuclear cells produce a soluble factor that produces a reversible severe depression of cardiac function. (J. Clin. Invest. 1990. 86:845-850.) Key words: interleukin 2 - lymphokine-activated killer cells • cardiac dysfunction • cardiotoxicity
\end{abstract}

\section{Introduction}

Since the T cell growth factor IL 2 was described (1), there have been numerous reports concerning its use in adoptive immunotherapy of metastases from various tumor types (2-9). Lymphocytes cultured with recombinant IL 2 are transformed into lymphokine-activated killer (LAK) ${ }^{1}$ cells which are capable of lysing tumor cells but show little or no lytic activity toward normal cells (10). Unfortunately, patients receiving IL 2 therapy develop a number of toxicities including, fever,

Address reprint requests to Dr. P. A. Sobotka, Department of Medicine, Loyola University of Chicago, Stritch School of Medicine, 2160 South First Avenue, Maywood, IL 60153.

Received for publication 27 July 1989 and in revised form 27 May 1990.

1. Abbreviations used in this paper: KHB, Krebs-Henseleit buffer; LAK, lymphokine-activated killer cells.

J. Clin. Invest.

(c) The American Society for Clinical Investigation, Inc.

0021-9738/90/09/0845/06 \$2.00

Volume 86, September 1990, 845-850 chills, anemia, eosinophilia, hyperbilirubinemia, oliguria, weight gain, gastrointestinal symptoms, peripheral and pulmonary edema, and hypotension $(2,3)$. Of these toxicities, the cardiovascular side effects are dose limiting for this immunotherapy regimen.

IL 2 induces a hemodynamic state that mimics that seen in patients with septic shock. Patients receiving IL 2 exhibited hypotension, decreased systemic vascular resistance, increased heart rate, and an increased cardiac index (11). Similar findings have been reported by others (7). These hemodynamic changes associated with this immunotherapy have been attributed, in part, to an increase in capillary permeability, giving rise to a "third-space syndrome" $(2,3,12-14)$. However, the possibility that IL 2 alone or in combination with LAK cells may have direct, deleterious influences on the heart has not been addressed.

The goal of the present investigation was to investigate the effects of both IL 2 alone and the supernatants from human mononuclear cells incubated with IL 2 on myocardial performance using the isolated, perfused, working rat heart preparation. This model allows the determination of cardiac output and coronary flow under fixed loading conditions. Thus, the model avoids many of the complications in interpretation that may be caused by peripheral actions of IL 2 or LAK cells.

\section{Methods}

Animal preparation. Male Sprague-Dawley rats weighing between 250 and $350 \mathrm{~g}$ were anesthetized with an intraperitoneal injection of 65 $\mathrm{mg} / \mathrm{kg}$ sodium pentobarbital. The abdomen was then opened and the animals were anticoagulated with $2 \mathrm{ml}$ of 1:1,000 heparin sodium injected into the inferior vena cava. $1 \mathrm{~min}$ was allowed for the heparin to circulate. The chest was then opened and the heart was removed within $20 \mathrm{~s}$ after opening the diaphragm. The heart was immediately immersed into a $4^{\circ} \mathrm{C}$ bath of heparinized Krebs-Henseleit buffer (KHB) solution. Contractile activity usually stopped within $15 \mathrm{~s}$. The blotted wet weight was obtained after trimming away excess tissue (lungs, vessels, pericardium, and fat). The aorta was quickly prepared for cannulation.

Isolated heart preparation. The isolated working rat heart model initially described by Neely and co-workers (15) has been modified for use with the addition of an electromagnetic flow probe in the afterload column and with the perfusate temperature maintained at $37^{\circ} \mathrm{C}$. The standard perfusion medium was a modified $\mathrm{KHB}$, containing (in millimolar): $\mathrm{NaCl}, 118 ; \mathrm{KCl}, 4.7 ; \mathrm{MgSO}_{4}, 1.2 ; \mathrm{NaHCO}_{3}, 25 ; \mathrm{KH}_{2} \mathrm{PO}_{4}$, $1.2 ; \mathrm{CaCl}_{2}, 2.5$; and dextrose, 10 .

The heart was placed on the perfusion apparatus by attaching the aorta to the perfusion apparatus cannula with a silk ligature $2-3 \mathrm{~mm}$ past the ostia of the coronary arteries. The stopcock was opened, allowing retrograde perfusion to begin. The heart resumed beating within seconds after the retrograde perfusion had begun. The pulmonary artery was opened to decompress the right ventricle. A second cannula was then inserted into the left atrium and secured. A bipolar electrode was attached to the right atrial appendage and paced at 300 $\mathrm{bpm}$ for the remainder of the experiment. After a 15-min period of retrograde perfusion with perfusion of oxygenated $\mathrm{KHB}$ at $90 \mathrm{cmH}_{2} \mathrm{O}$ perfusion pressure (left atrium unloaded), the preparation was 
switched to the working mode by allowing oxygenated KHB to enter the left atrium at a fixed preload and subsequently to be pumped out of the left ventricle into an afterloaded column. Aortic flow was measured by $(a)$ timed collections of ejected perfusate from the overflow of the afterload column and $(b)$ continuous recording of the mean flow measured by the electromagnetic flow probe (Carolina Medical Electronics, King, NC). Mean and pulsatile aortic flow were recorded continuously on a Gould recorder (model 2400S; Gould, Inc., Cleveland, $\mathrm{OH})$. Coronary flow was measured by the timed collection of pulmonary artery effluent. The mean cardiac output was computed by combining the aortic flow with the measured coronary flow rate.

Perfusion media. IL 2 was stock KHB supplemented with $0,1,100$, or $10,000 \mathrm{U}$ of IL $2 / \mathrm{ml}(n=24)$. IL 2-Media was stock KHB diluted 7:3 $\mathrm{vol} / \mathrm{vol}$ with cell culture media supplemented with $1,500 \mathrm{U}$ IL $2 / \mathrm{ml}$ ( $n$ $=11)$. LYMPH was stock KHB diluted 7:3 vol/vol with cell culture media in which healthy volunteer mononuclear cells had been cultured (without IL 2) for $3 \mathrm{~d}$ and removed $(n=6)$. LAK was stock KHB diluted 7:3 vol/vol with cell culture media in which mononuclear cells harvested from patients receiving IL 2/LAK therapy had been cultured for $3 \mathrm{~d}$ in the presence of $1,500 \mathrm{U} / \mathrm{ml}$ IL 2 . The cells were removed before perfusion $(n=9)$. For washout (W/O), after $20 \mathrm{~min}$ of perfusion with the LAK perfusion media, the media were exchanged for standard KHB to determine if the effects were reversible $(n=5)$.

Reagents. Recombinant IL 2 used in these studies was kindly provided by Cetus Corp. (Emeryville, CA).

Generation of cytokine-containing supernates. PBMC from normal donors were obtained (16). Briefly, peripheral blood was diluted 1:2 with HBSS and overlaid onto lymphocyte separation media (Organon Technika, Durham, NC). After centrifugation, the lymphocyteenriched interface was collected, washed three times with HBSS containing 5\% fetal bovine serum, and then resuspended at a concentration of $3 \times 10^{6}$ cells $/ \mathrm{ml}$ in serum-free complete media, Ex Vivo 10 (M.A. Bioproducts, Walkersville, MD). PBMC from IL 2/LAK patients were obtained by leukopheresis (2). These cells were washed three times in saline and then resuspended in Ex Vivo 10 media at 3 $\times 10^{6}$ cells $/ \mathrm{ml}$. IL 2 was added to the cell suspensions at a final concentration of $1,500 \mathrm{U} / \mathrm{ml}$. The cells were then aliquoted into tissue culture flask (Fenwal Laboratories, Round Lake, IL) and incubated in a humidified $5 \% \mathrm{CO}_{2}$ chamber.

After 3 or $4 \mathrm{~d}$ incubation, cells were pelleted by centrifugation $(900$ $g$ for $10 \mathrm{~min}$ ) and supernates were collected. These supernates (LAK) were stored at $4^{\circ} \mathrm{C}$ until use. Control supernates used in these experiments were obtained by incubating lymphocytes for $3 \mathrm{~d}$ without IL 2 (LYMPH) or by adding $1,500 \mathrm{U} / \mathrm{ml}$ IL 2 to the ex vivo 10 media without lymphocytes (IL 2-media).

Experimental protocol. Experiments were begun by taking initial cardiac output and coronary flow measurements in a working (left atrium loaded with the recirculating buffer) mode. The hearts were then temporarily placed in a retrograde (left atrium unloaded, perfusion with stock $\mathrm{KHB}$ at $90 \mathrm{~cm} \mathrm{H}_{2} \mathrm{O}$ perfusion pressure) fashion while the recirculating perfusate reservoir was replaced with one of the experimental media. This exchange took no longer than $2 \mathrm{~min}$, after which the heart was restored to the working mode. Cardiac function returned to baseline in all hearts after this exchange. Cardiac output and coronary flow were measured at 20 -min intervals throughout the experiment while preload was held constant at $10 \mathrm{~cm} \mathrm{H}_{2} \mathrm{O}$ and the afterload varied from $70,80,90$, and $100 \mathrm{~cm} \mathrm{H}_{2} \mathrm{O}$. A second series of measurements was made while the afterload was held constant at $90 \mathrm{~cm} \mathrm{H}_{2} \mathrm{O}$ and the preload was varied from $10,15,12,7$, and $5 \mathrm{~cm} \mathrm{H}_{2} \mathrm{O}$.

At the end of the experiment, the heart weight was again measured. The left and right ventricular wet weights were obtained after dissection of the right ventricular free wall and atrial chambers. Dry weights were obtained after the heart was dried in a vacuum oven for $72 \mathrm{~h}$ at $60^{\circ} \mathrm{C}$.

Data analysis. Cardiac output and coronary flow were normalized to cardiac wet weight and expressed in $\mathrm{ml} / \mathrm{min}$ per $\mathrm{g}$ wet left ventricle. All values are expressed as the mean \pm SEM. Differences between spe-
Table I. Weights (grams) and Wet/Dry Ratios

\begin{tabular}{lcccc}
\hline \multicolumn{1}{c}{ Group } & Preinfusion & Postinfusion & $\Delta$ Weight & Wet/Dry LV \\
\hline IL 2-Media & $1.09 \pm 0.07$ & $1.37 \pm 0.09$ & $0.27 \pm 0.04$ & $5.36 \pm 0.16$ \\
LAK & $1.07 \pm 0.05$ & $1.37 \pm 0.06$ & $0.30 \pm 0.04$ & $4.98 \pm 0.22$ \\
LYMPH & $1.01 \pm 0.09$ & $1.28 \pm 0.10$ & $0.28 \pm 0.03$ & $5.29 \pm 0.19$ \\
WASH & $1.06 \pm 0.12$ & $1.38 \pm 0.15$ & $0.31 \pm 0.03$ & $5.15 \pm 0.08$
\end{tabular}

Wet to dry heart weights between groups and before and after perfusion. All groups demonstrated a significant increase in weight with perfusion $(P<0.05)$ and no significant difference between groups was observed.

cific group means were tested using a two-way ANOVA with repeated measurements over time. Specific group comparisons then performed by modified $t$ test, with the variance obtained from the ANOVA.

\section{Results}

Heart weights. The wet heart weights ranged from 0.92 to 1.22 $\mathrm{g}$ with no significant differences between groups. After desiccation, the dry left ventricular weights ranged from 0.148 to $0.156 \mathrm{~g}$, again with no significant differences between all groups. All hearts gained weight during the 90 -min perfusion but there was no significant difference between groups. The mean heart weights, and weight change during the protocol is shown in Table I.

Cardiac output. Hearts perfused with KHB supplemented with $0,1,100$, or $10,000 \mathrm{U}$ of IL $2 / \mathrm{ml}$ demonstrated no changes in cardiac output during the monitoring period. Fig. 1 shows the cardiac function curves for each concentration. Cardiac output at $90 \mathrm{~cm} \mathrm{H}_{2} \mathrm{O}$ afterload was similar and not significantly different between the control group (IL $2=0 \mathrm{U} / \mathrm{ml}$ ) and the groups receiving different concentrations of IL 2 at each preload tested. Thus, IL 2 alone had no effect on cardiac output.

The effects of perfusion with IL 2-Media, LYMPH, and LAK on cardiac output as a function of time are shown in Fig. 2. Neither IL 2-Media or LYMPH had a significant effect on cardiac output during the 60 -min monitoring period. However, LAK media induced a significant reduction $(\% \Delta=32 ; P$ $<0.001$ ) of cardiac output by $20 \mathrm{~min}$ of perfusion. Cardiac output continued to fall during the remainder of the experiment to $\sim 46 \%$ of the control value after $60 \mathrm{~min}$ of exposure.

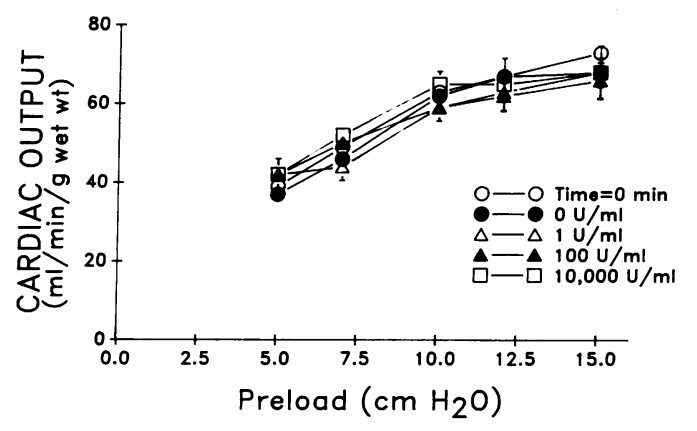

Figure 1. Cardiac output ( $\mathrm{ml} / \mathrm{min}$ per $\mathrm{g}$ wet weight) vs. preload $\left(\mathrm{cmH}_{2} \mathrm{O}\right)$ in hearts perfused with $\mathrm{KHB}$ supplemented with different concentrations of IL 2. No significant difference between groups. 


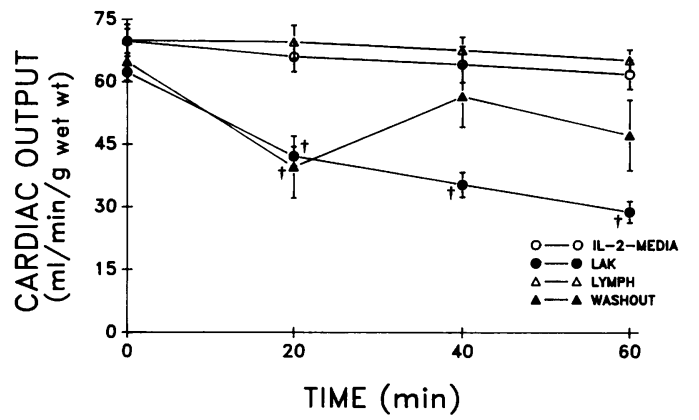

Figure 2. The changes in cardiac output as a function of time observed with perfusion with IL 2-Media, LAK, LYMPH, or with LAK followed by a washout phase. $\dagger P<0.001$ compared with IL 2 -media and LYMPH.

This reduction could be partially reversed by "washing-out" with standard KHB solution if the heart solution exchange took place after only 20 min of exposure to the LAK media, with cardiac output falling from $64.8 \pm 4.5 \mathrm{ml} / \mathrm{min}$ per $\mathrm{g} \mathrm{LV}$ at time $=0$ falling to $39.5 \pm 7.5$, and recovering to $56.5 \pm 7.4$ at 40 $\mathrm{min}$ and $47.3 \pm 8.5 \mathrm{ml} / \mathrm{min}$ per $\mathrm{g} \mathrm{LV}$ at $60 \mathrm{~min}$. After $60 \mathrm{~min}$ of exposure to LAK media, no recovery of function could be obtained by exchanging the media for standard KHB. LAK solutions boiled at $100^{\circ} \mathrm{C}$ for 5 min caused no reduction in cardiac function $(n=2)$.

Coronary flow. With the preload fixed at $10 \mathrm{~cm} \mathrm{H}_{2} \mathrm{O}$, coronary flow increased for each increment of afterload from 70 to $100 \mathrm{~cm} \mathrm{H}_{2} \mathrm{O}$. Coronary flow rates ranged from $64 \pm 3$ to $108 \pm 3$ for 70 and $100 \mathrm{~cm} \mathrm{H}_{2} \mathrm{O}$ afterload, respectively. This response was seen in all groups, with no significant differences seen between groups.

The effects of perfusion with IL 2-Media $(10,000 \mathrm{U} / \mathrm{ml})$, LYMPH, and LAK on coronary flow as a function of time are shown in Fig. 3. Perfusion with IL 2-Media or LYMPH did not alter coronary flow over the 60 -min experimental period. However, LAK media induced a significant reduction of coronary flow $(\% \Delta=19)$ by $20 \mathrm{~min}$ of perfusion. Similar to the changes observed in cardiac output, this reduction in coronary flow persisted for the remainder of the experiment to $\sim 67 \%$ of the control value after $60 \mathrm{~min}$ of perfusion. The reduction of coronary flow could be partially and temporarily attenuated by exchanging the LAK perfusion media with standard KHB perfusate.

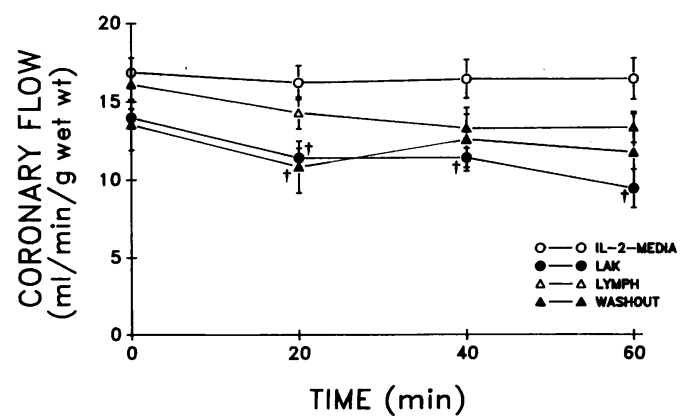

Figure 3. The changes in coronary flow as a function of time observed with perfusion with IL 2-Media, LAK, LYMPH, or with LAK followed by a washout phase. No significant difference between groups.
Ventricular function curves were constructed using the data from time $=0$ and after $60 \mathrm{~min}$ of perfusion with each of the solutions. With the afterload held constant, at $90 \mathrm{~cm} \mathrm{H}_{2} \mathrm{O}$, preload was sequentially changed from $10,12,15,7$, and $5 \mathrm{~cm}$ $\mathrm{H}_{2} \mathrm{O}$ while cardiac output was continuously measured. The control ventricular function curves (time $=0$ ) are shown in Fig. $4 \mathrm{~A}$. There were no significant differences between IL 2-Media, LYMPH and LAK groups in cardiac output in response to the increases in preload. The ventricular function curves constructed from the values obtained after $60 \mathrm{~min}$ of perfusion are shown in Fig. $4 \mathrm{~B}$. The ventricular function curves remained essentially unchanged in the IL 2-Media and LYMPH group after 60 min of perfusion. However, after 60 min of perfusion with LAK media, there was a significant depression of cardiac function. At $5 \mathrm{~cm} \mathrm{H} \mathrm{H}_{2} \mathrm{O}$, the cardiac output was decreased by $30 \%$, and by $59 \%$ at $15 \mathrm{~cm} \mathrm{H}_{2} \mathrm{O}$ as compared with control $(P<0.001)$. In the LAK treated group at time $=0$, increasing the preload from 5 to $15 \mathrm{~cm} \mathrm{H}_{2} \mathrm{O}$, increased cardiac output by $106 \%$. After 60 min of LAK perfusion, the same increase in preload increased cardiac output by only $50 \%$. Thus, not only were the absolute levels of cardiac output reduced at each preload after $60 \mathrm{~min}$ of perfusion with LAK media, but the ability of the left ventricle to respond to changes in preload was also severely depressed.

Ventricular function curves were also constructed for the conditions of a fixed preload while afterload was changed at time $=0$, and after 60 min of perfusion. These are shown in Fig. 5. Increasing afterload in this range $\left(70-100 \mathrm{~cm} \mathrm{H}_{2} \mathrm{O}\right)$ did not significantly alter cardiac output in any of the three groups at time $=0$ (Fig. $5 \mathrm{~A}$ ). After $60 \mathrm{~min}$ of perfusion (Fig. $5 \mathrm{~B}$ ), cardiac outputs in the IL 2-Media and LYMPH groups were slightly depressed at each afterload $(P>0.05)$ compared with time 0 . However, the LAK treated group showed a significant depression of cardiac output at each afterload $(P<0.005)$ compared to time 0 , and dramatically reduced $(P<0.0001)$ function compared with all other media at time $=60 \mathrm{~min}$.

The changes in coronary flow with the preload fixed at 10 cm $\mathrm{H}_{2} \mathrm{O}$ and afterload varied form 70 to $100 \mathrm{~cm} \mathrm{H}_{2} \mathrm{O}$ at time $=060 \mathrm{~min}$ are shown in Table II. As expected, coronary flow increased as a function of afterload in all groups at time $=0$. After $60 \mathrm{~min}$ of perfusion, the absolute level of coronary flow was depressed in both the LYMPH and LAK groups. However, coronary flows increased in all three groups in response to the increase in afterload. The absolute decrease of coronary flow in the 60-min LAK group is most likely attributable to the reduced contractility and reduced myocardial demand for substrate. The vasculature retains its ability to appropriately vasodilate in response to increases of afterload and myocardial work.

\section{Discussion}

The findings of the present investigation demonstrate that neither IL 2 nor mononuclear cells in culture alone caused a decrease in cardiac output. However, the supernatant of lymphocytes cultured in media supplemented with IL 2 contains a factor that causes a significant depression of myocardial function. The isolated, perfused working rat heart model allows quantification of myocardial function without the complicating influences of uncontrolled loading conditions, activated blood products, or alterations of substrate availability (oxygen, 

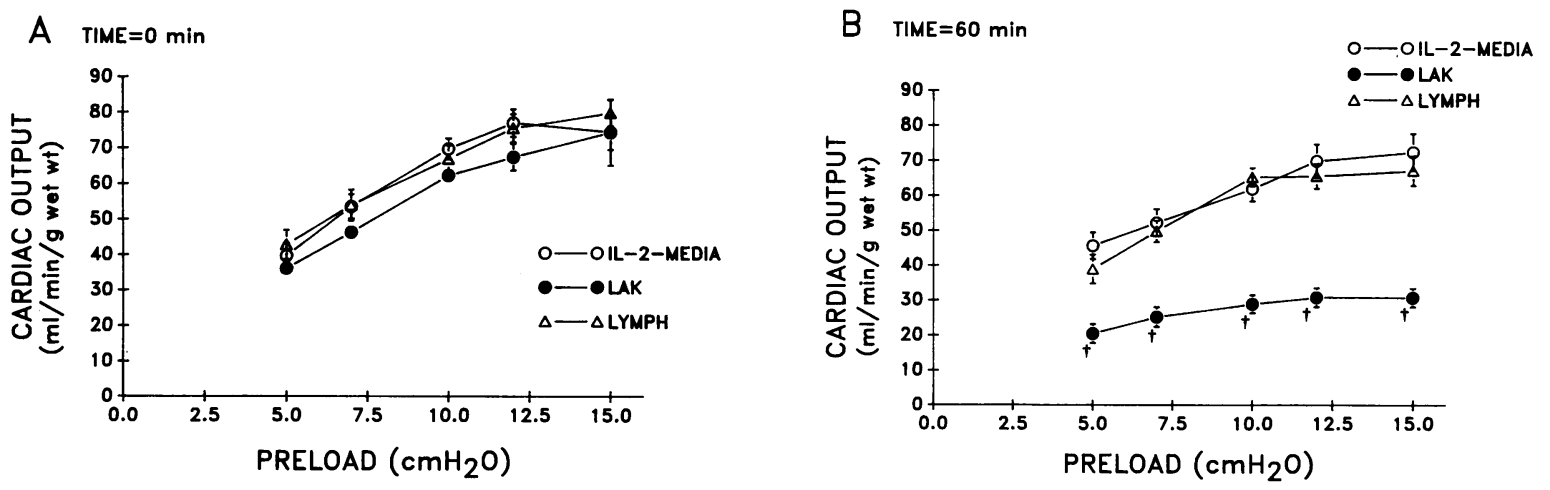

Figure 4. Cardiac function curves plotting cardiac output as a function of preload. $(A)$ The points in these curves were obtained as soon as the preparations had stabilized and before the perfusion media had been changed (time $=0)$. No significant difference between groups. $(B)$ Function curves obtained from points taken at $60 \mathrm{~min}$. Note the depression of the LAK curve. $\dagger P<0.001$ at all preloads.

glucose). The exact mechanism for the observed decrease of function is not known. However, the direct effects of the product(s) of stimulated lymphocytes on the heart have been examined in the absence of the reported peripheral clinical toxicities such as peripheral vasodilation and capillary leak $(2,3,7$, 11-14). Note that the model itself precludes the possibility of peripheral events. Although, the end-diastolic pressure was held constant and the end-diastolic volume was not controlled; thus the possibility that a change in chamber compliance with subsequent alterations in the absolute preload occurred cannot be eliminated. However, the ventricular function curves of both time 0 and 60 min approach a plateau for all solutions, suggesting that a change in compliance was not a major contributing factor to the observed change in ventricular function. For compliance alterations to explain the observed fall in stroke volume, increases of preload should not have resulted in diminishing increments of stroke volume (plateau effect). Thus, stimulation of cultured lymphocytes by IL 2 produces a factor that directly reduces myocardial contractile function.

Table II. Changes in Coronary Flow with Afterload

\begin{tabular}{|c|c|c|c|}
\hline \multicolumn{4}{|c|}{ Time $=0 \min$} \\
\hline \multicolumn{4}{|l|}{$\mathrm{cm} \mathrm{H}_{2} \mathrm{O}$} \\
\hline 70 & $13.53 \pm 0.71$ & $13.67 \pm 0.88$ & $11.20 \pm 0.86$ \\
\hline 80 & $15.79 \pm 0.78$ & $15.50 \pm 1.31$ & $13.02 \pm 0.77$ \\
\hline 90 & $16.88 \pm 0.94$ & $16.12 \pm 0.99$ & $13.98 \pm 0.57$ \\
\hline 100 & $19.72 \pm 1.01$ & $17.67 \pm 1.56$ & $16.72 \pm 0.92$ \\
\hline \multicolumn{4}{|c|}{ Time $=60 \mathrm{~min}$} \\
\hline \multicolumn{4}{|l|}{$\mathrm{cm} \mathrm{H}_{2} \mathrm{O}$} \\
\hline 70 & $13.78 \pm 1.41$ & $11.00 \pm 0.95$ & $8.03 \pm 1.39^{*}$ \\
\hline 80 & $14.58 \pm 1.44$ & $12.40 \pm 1.29$ & $9.22 \pm 1.40^{*}$ \\
\hline 90 & $16.45 \pm 1.32$ & $13.33 \pm 0.99$ & $9.41 \pm 1.24^{*}$ \\
\hline 100 & $16.31 \pm 1.12$ & $14.74 \pm 1.46$ & $11.58 \pm 1.65^{*}$ \\
\hline
\end{tabular}

Changes in coronary flow with the preload fixed at $10 \mathrm{~cm} \mathrm{H}_{2} \mathrm{O}$ an afterload varied from $\left(70-100 \mathrm{~cm} \mathrm{H}_{2} \mathrm{O}\right)$ at time $=0$, and at time $=60$ $\mathrm{min}$. After $60 \mathrm{~min}$ of perfusion, the absolute level of coronary flow was depressed in both the LYMPH and LAK groups $\left({ }^{*} P<0.05\right)$.
This reduction in myocardial function appears to be partially reversible if the factor is "washed-out" early after myocardial exposure. Furthermore, that this factor can be destroyed by boiling suggests that it is a heat-labile protein. The proteins made by activated lymphocytes are numerous. They include tumor necrosis factor- $\alpha$, IL I-VII, and $\alpha$-IFN. Lymphocytes do not produce oxygen-derived free radicals such as myeloperoxidase, superoxide anion, and hydrogen peroxide, the products of activated neutrophils. The lymphocyte isolation procedure used in this study rigorously excludes neutrophils and does not allow mast cells to survive in culture. Thus, the products of stimulated lymphocytes, the lymphocytes, are unlike the neutrophil products which have already been reported to alter cardiac function. In the present series of experiments, the period of exposure to the media was brief. The effects of longer perfusion periods and the potential for recovery after prolonged exposure will require further investigation.

The observed gain of wet weight throughout the experimental period was observed in all groups. Conceivably, myocardial interstitial edema could contribute to the cardiac dysfunction observed in the LAK group. Interstitial edema has been reported in patients receiving IL 2 therapy (13). Increased microvascular permeability in the lung (12), and blood-brain barrier dysfunction (14) have also been reported after IL 2 administration. However, the change of wet weight and the wet/dry ratio measured in the LAK treated hearts was not significantly different from the changes seen in the other groups. This suggests that water accumulation or capillary leak syndrome is not responsible for the changes of ventricular function observed in these experiments. The distribution of weight gain was not examined; conceivably it is possible that LAK-treated hearts have an interstitial or intracellular edema not observed in the control populations.

The alterations in coronary flow during the perfusion period were not significantly different between groups. After 60 min of exposure to the LAK media, the decrease in coronary flow is slightly greater than that seen in the other groups. However, the decrease in function was also the greatest in this group. In all groups, increasing afterload resulted in an increase in coronary flow. In addition, the preservation of responsiveness of coronary flow to increased afterload suggests that the observed reduction of coronary flow was in response to reductions in ventricular function, and myocardial demand 

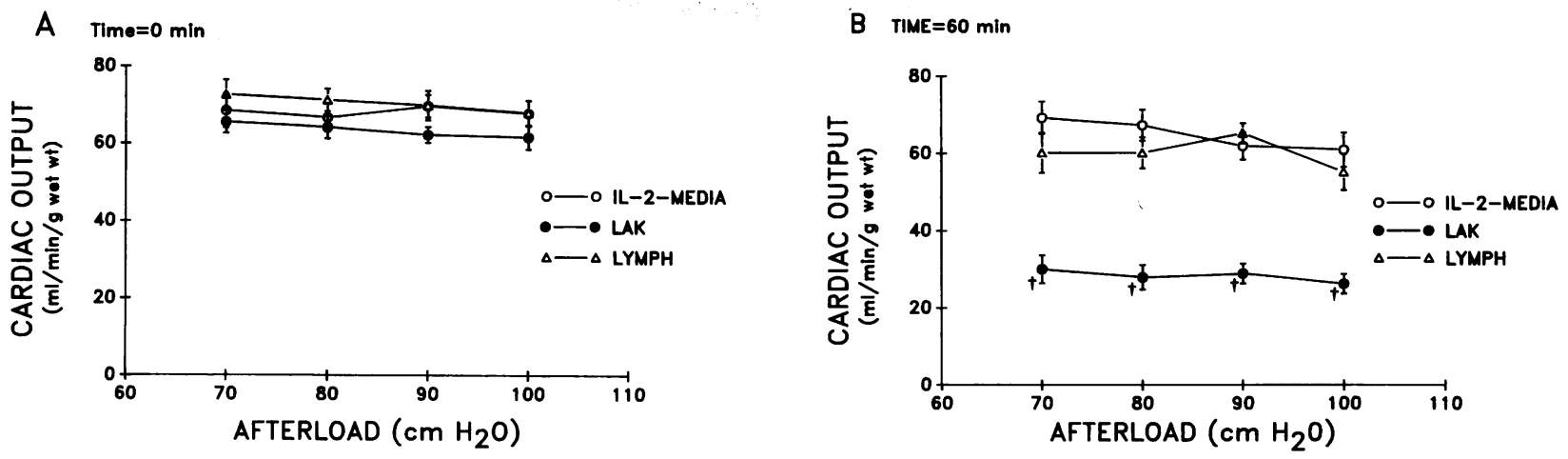

Figure 5. Cardiac function curves plotting cardiac output as a function of afterload. $(A)$ The points in these curves were obtained as soon as the preparations had stabilized and before the perfusion media had been changed (time $=0)$. No significant difference between groups. $(B)$ Function curves obtained from points taken at $60 \mathrm{~min}$. Note the depression of the LAK curve. $\uparrow P<0.001$ at all afterloads.

for substrates. The possibility that the reduced coronary flow occurred in response to a direct vasoconstriction in the coronary circulation cannot be excluded. However, the hemodynamic response in the periphery is suggestive of a vasodilatory action, not vasoconstrictive.

These negative inotropic events have been occasionally reported in clinical studies of IL 2/LAK chemotherapy patients. Ognibene et al. (7) have documented a decrease in ejection fraction relative to baseline in three patients treated with IL 2. Dramatic hemodynamic alterations to IL 2 and IL 2/LAK chemotherapy have been reported. These alterations include: reductions of peripheral vascular resistance associated with severe hypotension, pulmonary edema, and peripheral edema formation. These alterations have responded with fluid resuscitation and the addition of pressor agents. Gaynor et al. reported that the cardiac output was elevated in the face of an abnormally low systemic vascular resistance, and cardiac output was further augmented by the addition of dopamine (11). It was not possible to assess cardiac output independently of loading conditions. Therefore, some depression of cardiac function may have been present, but not detected. Recently, another product of activated lymphocytes, IFN- $\alpha$ was reported to cause a reversible cardiac dysfunction in patients receiving immunotherapy for Kaposi's sarcoma. Three patients with AIDS and Kaposi's sarcoma developed congestive cardiomyopathy with profound ventricular dysfunction in association with lymphokine therapy (17). Also, there has been a case report of a fatal episode of congestive heart failure developing in a patient with renal cell carcinoma who was receiving IFN- $\alpha_{2}$ therapy (18).

Immunotherapy with IL 2/LAK has been shown to induce responses in some malignancies refractory to conventional therapies e.g., malignant melanoma and renal cancer $(4,9)$. The treatment is, however, limited due to many serious and toxic side effects. If the severe hypotension observed in this immunotherapy is potentially compounded by direct myocardial depression due to a soluble product of IL 2-stimulated lymphocytes, treatment strategies will have to protect against this complication. Further research into the mechanism, action, and biochemical nature of this factor are needed.

In summary, IL 2-stimulated/cultured human mononuclear cells produce a soluble factor that produces a reversible severe depression of cardiac function. This depression of car- diac function may be due to either a primary reduction of contractility or a reduction of ventricular compliance. Early washout of the factor allows recovery of myocardial function.

\section{Acknowledgments}

This work was supported in part by National Cancer Institute NO1CM-73704 and from the Earl M. Bane Charitable Trust Fund.

\section{References}

1. Morgan, D. A., F. W. Ruscetti, and R. G. Gallo. 1976. Selective in vitro growth of $\mathrm{T}$ lymphocytes from normal human bone marrows. Science (Wash. DC). 193:1007-1008.

2. Rosenberg, S. A., M. T. Lotze, L. M. Muul, S. Leitman, A. E. Chang, S. E. Ettinghausen, Y. L. Matory, J. M. Skibber, E. Shiloni, J. T. Vetto, C. A. Seipp, C. Simpson, and C. M. Reichert. 1985. Observations on the systemic administration of autologous lymphokine-activated killer cells and recombinant interleukin-2 to patients with metastatic cancer. N. Engl. J. Med. 313:1485-1492.

3. Lotze, M. T., Y. L. Matory, A. A. Rayner, S. E. Ettinghausen, J. T. Vetto, C. A. Seipp, and S. A. Rosenberg. 1986. Clinical effects and toxicity of interleukin-2 in patients with cancer. Cancer. 58:27642772.

4. Rosenberg, S. A., M. T. Lotze, L. M. Muul, A. E. Chang, F. P. Avis, S. Leitman, W. M. Lineham, G. N. Robertson, R. E. Lee, J. T. Rubin, C. A. Seipp, C. G. Simpson, and D. E. White. 1987. A progress report on the treatment of 157 patients with advanced cancer using lymphokine-activated killer cells and interleukin- 2 or high-dose interleukin-2 alone. N. Engl. J. Med. 316:889-897.

5. Lotze, M. T., A. E. Chang, C. A. Seipp, C. Simpson, J. T. Vetto, and S. A. Rosenberg. 1986. High-dose recombinant interleukin 2 in the treatment of patients with disseminated cancer: responses, treatment-related morbidity, and histologic findings. JAMA (J. Am. Med. Assoc.). 256:3117-3124.

6. Belldegrun, A., D. E. Webb, H. A. Austin III, S. M. Steinberg, D. E. White, W. M. Linehan, and S. A. Rosenberg. 1987. Effects of interleukin-2 on renal function in patients receiving immunotherapy for advanced cancer. Ann. Int. Med. 106:817-822.

7. Ognibene, F. P., S. A. Rosenberg, J. M. Skibber, J. H. Shelhamer, M. T. Lotze, and J. E. Parrillo. 1986. Interleukin-2 produces hemodynamic changes similar to septic shock in humans. Crit. Care Med. 14:352A. (Abstr.)

8. West, W. H., K. W. Tauer, J. R. Yannelli, G. D. Marshall, D. W. Orr, G. B. Thurman, and R. K. Oldham. 1987. Constant-infusion 
recombinant interleukin-2 adoptive immunotherapy of advanced cancer. N. Engl. J. Med. 316:898-905.

9. Fisher, R. I., C. A. Coltman, Jr., J. H. Doroshow, A. A. Rayner, M. J. Hawkins, J. W. Mier, P. Wiernik, J. D. McMannis, G. R. Weiss, K. A. Margolin, B. T. Gemlo, D. F. Hoth, D. R. Parkinson, and E. Paietta. 1988. Metastatic renal cancer treated with interleukin-2 and lymphokine-activated killer cells. Ann. Int. Med. 108:518-523.

10. Grimm, E. A., A. Mazumder, H. Z. Zhang, and S. A. Rosenberg. 1982. Lymphokine activated killer cell phenomenon: lysis of natural killer resistant fresh solid tumor cells by interleukin-2 activated autologous human peripheral blood lymphocytes. J. Exp. Med. 155:1823-1841.

11. Gaynor, E. R., L. Vitek, L. Sticklin, S. P. Creekmore, M. E. Ferraro, J. X. Thomas, Jr., S. G. Fisher, and R. I. Fisher. 1988. The hemodynamic effects of treatment with interleukin-2 and lymphokine-activated killer cells. Ann. Int. Med. 109:953-958.

12. Fairman, R. P., F. L. Glauser, R. E. Merchant, D. Bechard, and A. A. Fowler. 1987. Increase of rat pulmonary microvascular permeability to albumin by recombinant interleukin-2. Cancer Res. 47:3528-3532.

13. Rosenstein, M., S. E. Ettinghausen, and S. A. Rosenberg. 1986.
Extravasation of intravascular fluid mediated by the systemic administration of recombinant interleukin 2. J. Immunol. 137:1735-1742.

14. Ellison, M. D., J. T. Povlishock, and R. E. Merchant. 1987. Blood-brain barrier dysfunction in cats following recombinant interleukin-2 infusion. Cancer Res. 47:5765-5770.

15. Neely, J. R., H. Liebermeister, E. J. Battersby, and H. E. Morgan. 1967. Effect of pressure development on oxygen consumption by isolated rat heart. Am. J. Physiol. 212:804-814.

16. McMannis, J. D., R. I. Fisher, S. P. Creekmore, D. P. Braun, J. E. Harris, and T. M. Ellis. 1988. In vivo effects of recombinant IL-2. I. Isolation of circulating Leu- $19^{+}$lymphokine activated killer effector cells from cancer patients receiving recombinant IL-2. J. Immunol. 140:1335-1340.

17. Deyton, L. R., R. E. Walker, J. A. Kovacs, B. Herpin, M. Parker, H. Masur, A. S. Fauci, and H. C. Lane. 1989. Reversible cardiac dysfunction associated with interferon alfa therapy in AIDS patients with Kaposi's Sarcoma. N. Engl. J. Med. 321:1246-1249.

18. Cohen, M. C., M. S. Huberman, and R. W. Nestro. 1988. Recombinant alpha-2 interferon related cardiomyopathy. Am. J. Med. 85:549-551. 